\title{
CAMADA POPULAR EMERGENTE: UM NOVO CONTEXTO PARA A COMUNICAÇÃO PUBLICITÁRIA DE INSTITUIÇÕES DE ENSINO SUPERIOR
}

\author{
POPULAR EMERGING SEGMENT: A NEW CONTEXT FOR ADVERTISING \\ COMMUNICATION TO HIGHER EDUCATION INSTITUTIONS.
}

\author{
CAMADA POPULAR EMERGENTE: UN NUEVO CONTEXTO PARA LA \\ COMUNICACIÓN PUBLICITÁRIA DE INSTITUCIONES DE EDUCACIÓN \\ SUPERIOR
}

\author{
Ewerton Mauro Visotto Faria \\ Mestre em Comunicação, USCS \\ evisotto@uol.com.br \\ Gino Giacomini Filho \\ Doutor e Livre-docente, ECA/USP. \\ gino.giacomini@uscs.edu.br
}

\section{Resumo}

Os cenários político, econômico e social vividos pelo Brasil nas últimas décadas trouxeram novos contextos para a comunicação, sendo o fenômeno da camada popular emergente um deles. Tal contingente revelou-se fundamental para a expansão das instituições de ensino superior (IES), o que demandou uso de estratégias de comunicação de marketing focadas nesse público. O objetivo é analisar a comunicação publicitária envolvida na relação das IES para com a camada popular emergente por uma pesquisa de natureza qualitativa e exploratória, referencial teórico e estudo documental por meio da análise de conteúdo de anúncios publicitários veiculados no jornal Metrô News, tipificado para a camada popular emergente. Os resultados apontam que a camada popular emergente oferece novos insumos para as decisões estratégicas das IES e para sua comunicação publicitária.

Palavras-chave: Comunicação publicitária. Camada popular emergente. Instituições de ensino superior.

\begin{abstract}
The politic, economic and social scenario experienced by Brazil in those last decades brought new contexts to communication, being the phenomenon of popular emerging segment one of these contexts. This segment become essential to development of higher education institutions (IES) motivating uses of marketing communication strategies focused in that public. The goal is to analyze the advertising communication involved in relation to the IES with the popular emerging segment by means a qualitative and exploratory research, and theoretical and documentary study with content analysis of advertisements broadcasted in Metro News newspaper, typified for this segment. The results point that the popular emerging segment offers new inputs to the strategic decisions of the IES and its advertising communication.
\end{abstract}

Keywords: Advertising communication. Popular emerging segment. Higher education institutions. 


\section{Resumen}

Los escenarios político, económico y social experimentados por Brasil en las últimas décadas han traído nuevos contextos para la comunicación, y el fenómeno de la camada popular emergente es uno de estos contextos. Dicho contingente fue crucial para la expansión de las instituciones de educación superior (IES), requiriendo el uso de estrategias de comunicación de marketing dirigidas a este público. El objetivo es analizar la comunicación publicitaria a respecto de las IES con la camada popular emergente por medio de una pesquisa cualitativa y exploratoria, e estudio teórico y documental mediante el análisis del contenido de los anuncios difundidos en el periódico Metrô News, que se caracteriza por su inserción en la camada popular emergente. Los resultados indican que la camada popular emergente ofrece nuevos insumos a las decisiones estratégicas de las IES y su comunicación publicitaria.

Palabras clave: Comunicación publicitaria. Camada popular emergente. Instituciones de educación superior.

Esta obra está licenciada sob uma Licença Creative Commons

\section{INTRODUÇÃO}

Reflexo dos cenários político, econômico, social e comunicacional que temos vivido a partir dos anos 1980, a estabilização da moeda, novas tecnologias virtuais, avanços da inclusão social, o incremento do poder aquisitivo e do poder de crédito impulsionam um novo segmento que podemos denominar "camada popular emergente" no Brasil. Tal contingente vem alterando a postura de empresas, inclusive instituições educacionais que se viam ancoradas em um perfil de público-alvo mais elitizado, mas que se encorajaram a adequar produtos e serviços para um público de menor poder aquisitivo, que recentemente também tem sido denominado por alguns de nova classe média.

Essa camada emergente, já pertencente a um estrato majoritário no Brasil, desperta nas organizações grande interesse mercadológico, demandando estratégias de marketing e de comunicação adequadas geralmente ancoradas no custo-benefício. Aspectos da comunicação publicitária revelam-se particularizados, mas ainda carentes de um desenvolvimento mais alinhado com os valores, aspirações e características dos que compõem tal segmento.

Em termos gerais, a estratégia de preço baixo possibilitou uma vantagem competitiva às instituições de ensino superior (IES) que se estruturaram para atender tal demanda, assim como uma comunicação especializada trabalhando elementos que remetessem ao "custo" ou custo-benefício. 
O objetivo deste estudo é analisar a comunicação publicitária envolvida na relação das IES para com a camada popular emergente.

De caráter exploratório e qualitativo, o estudo vale-se de estudo bibliográfico relativo aos eixos temáticos das IES, camada popular emergente, estratégias mercadológicas e comunicação publicitária. O trabalho oferece uma base conceitual para o termo "camada popular emergente", caracteriza estratégias mercadológicas para este público e para as IES direcionando a abordagem para análise de conteúdo de anúncios publicitários veiculados no jornal impresso Metrô News (São Paulo-SP, Brasil).

\section{CAMADA POPULAR EMERGENTE}

O Brasil vivenciou peculiar processo político, social e econômico nas últimas décadas.

O processo culmina nos anos 1980, a década da redemocratização, cujo ápice foi o movimento Diretas Já de 1984. Terminamos os anos 1980 com eleição direta para presidente, mas também com nossos recordes históricos de desigualdade e inflação, que marcariam a agenda das décadas seguintes. Os anos 1990 podem ser chamados de década da estabilização, após o advento do Plano Real em 1994. Em 2004, a redução da desigualdade vem acompanhada da volta do crescimento da economia e da aceleração de novos empregos com carteira. Ou seja, tivemos conquistas em dois de nossos históricos problemas coletivos, desigualdades e informalidade. Ao mesmo tempo, consolidamos as frentes de redemocratização e da estabilidade econômica. Depois das turbulências financeiras associadas ao pleito de 2002, a estabilidade econômica valeu como uma espécie de segundo Plano Real (NERI, 2011, p. 45).

Ainda no plano político, os governos Lula e Dilma implantaram programas para organizar e amenizar a questão da desigualdade social, como por exemplo: Auxílio-Gás, Bolsa-Família, Cartão-Alimentação do programa Fome Zero, Bolsa-Alimentação, BolsaEscola, PETI (Programa de Erradicação do Trabalho Infantil). E a oferta de programas sociais por parte do governo deve ainda aumentar, pois de acordo com O'Neill (2012, p. 63): “a democracia brasileira exigirá novos programas de grande escala para melhorar a qualidade da assistência médica e da educação e aumentar o uso de tecnologia".

Tais programas sociais tornam milhares de pessoas economicamente ativas ou com maior poder de consumo:

Esse crescimento da economia e do consumo interno levou o governo a arrecadar mais e gastar mais. E o governo gastou mais em dois pontos: na previdência e na criação de programas governamentais de inclusão. $\mathrm{Na}$ 
previdência milhões e milhões de aposentados tiveram aumento de seus proventos (TORRETA, 2009, p.63).

A "camada popular" corresponderia aos estratos de menor poder aquisitivo alinhados com boa parte das classes C, D e E.

Não existe um critério oficial ou consensual para caracterizar as "classes" socioeconômicas ou classes econômicas, nem, portanto, a quantidade de pessoas que pertenceriam a essas classes.

O critério Brasil de classificação econômica ${ }^{1}$ apega-se a nove regiões metropolitanas do Brasil para indicar a quantidade de pessoas que se enquadram nos respectivos estratos, de forma que a classe $\mathrm{C}(\mathrm{C} 1$ e $\mathrm{C} 2)$ é majoritária com 48,8\%, as classes D e E contariam com $14,9 \%$ e as classes A e B (A1, A2, B1, B2) com 36,3\%.

Em outro modelo representativo (Cetelem BGN/IPSOS Public Affairs), observa-se na Figura 1 que a classe $\mathrm{C}$ foi a que mais se expandiu e, ao se deter pelos dados da figura, aparentemente essa expansão ocorreu com a chegada de integrantes das classes D e E, já que considerada a diferença dos dados de 2005 e 2011, o aumento da classe C (40 milhões) é similar ao decréscimo das classes DE (47 milhões) ${ }^{2}$. A emergência das classes de menor poder revela-se consistente pois, aparentemente, muitos de seus integrantes conseguiram passar para as classes $\mathrm{AB}$, uma vez que este segmento registrou aumento de 16 milhões de pessoas.

Figura 1 - Mudança do perfil das classes socioeconômicas no Brasil (2005-2011) - IPSOS 2011
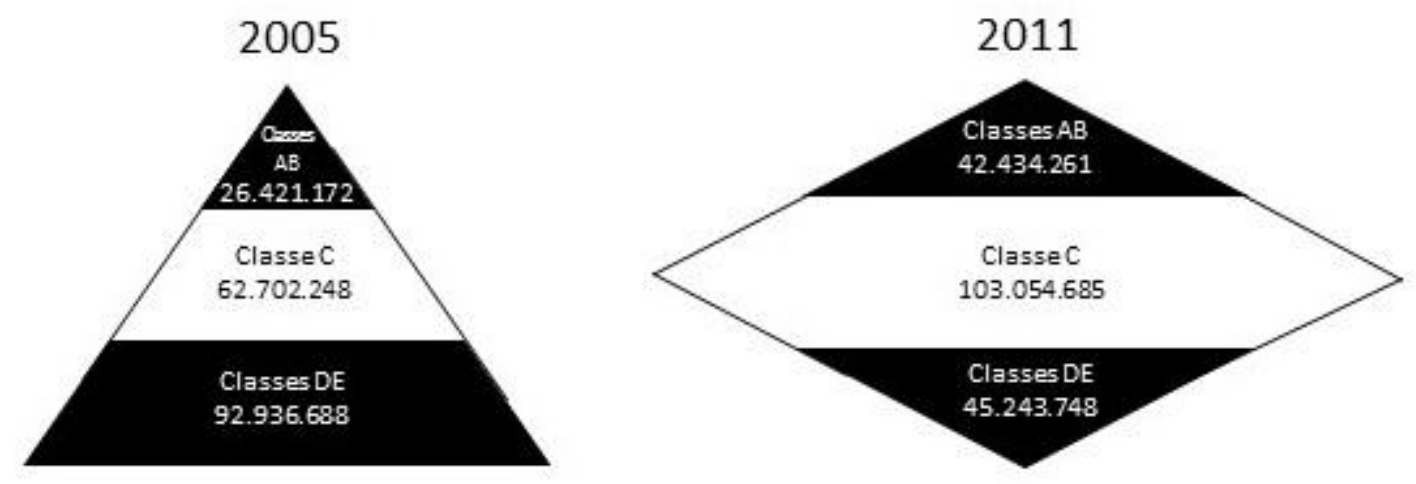

Segundo Romanelli (2003), abordar “camadas populares” está ligado diretamente à teoria de estratificação social, pois esta pressupõe que as camadas sociais podem sobrepor-se

${ }^{1}$ Dados com base no Levantamento Sócio Econômico 2011 - IBOPE. Fonte: ABEP, Associação Brasileira das Agências de Pesquisa. 2012. Disponível em http://www.abep.org/novo/Content.aspx?ContentID=835. Acesso em 20 dez. 2012.

${ }^{2}$ Pesquisa Cetelem BGN - IPSOS 2011. O Observador Brasil 2012. Disponível em http://www.cetelem.com.br/portal/Sobre_Cetelem/Observador.shtml. Acesso em 22 ago. 2012. 
e serem delimitadas, principalmente no que diz respeito à renda. De acordo com Earp e Paulani (2011, p.4) "ocorreu uma mudança no padrão de consumo de massa de bens duráveis no país, em paralelo com o crescimento e distribuição de renda”. Elementos simbólicos, valores sociais e culturais também são abordados por Romanelli (2003) no que se refere ao estilo de vida, inclusive das camadas populares, não dependendo somente de seus rendimentos, mas de um "equilíbrio" entre tais elementos.

As características que qualificam por "emergente", para Willians (2005, p.219) seriam "novos significados e valores, novas práticas, novas significações e experiências", fatores estes que evidenciam uma mudança de comportamentos, hábitos e, consequentemente, de consumo.

D’Andrea et al (2003) atribuem aos consumidores emergentes um nível econômico médio-baixo e um comportamento de consumo aspiracional, caracterizando-os com renda suficiente para gastar com bens e serviços em que a relação preço-qualidade é muito observada.

Podemos então definir por camada popular emergente o estrato social de pequeno poder aquisitivo, que passou ou passa por um processo de ascensão socioeconômica, adquirindo novas experiências, novas práticas, novos significados e novos valores de forma a remeter a um novo estilo de vida.

A educação, e em especial o ensino superior, passa a ser vista como algo mais próximo da realidade desse contingente. Melhor grau de instrução proporciona uma melhoria na condição social. O sonho de ter um diploma de curso superior parece ficar mais próximo e com ele novas possibilidades de ascensão social e econômica: acesso a profissões mais desejadas, melhor colocação profissional, maiores oportunidades no mercado de trabalho.

As IES entendem esse processo e organizam sua estrutura para receber esses "novos" ingressantes, tanto no que tange à flexibilidade de pagamento e horários, quanto ao material didático apresentado, bem como as parcerias com programas governamentais, a exemplo do ProUni, FIES, Escola da Família, entre outros. Segundo Souza e Lamounier (2010, p. 68), “[...] para os brasileiros, o diploma universitário representa, ao mesmo tempo, o símbolo e o instrumento de ascensão social, configurando uma expectativa concreta de aumento substancial da renda”. Os pais esforçam-se para oferecer aos filhos a educação superior à qual muitos deles não tiveram acesso quando jovens.

\section{ESTRATÉGIAS DE MARKETING E AS INSTITUIÇÕES DE ENSINO SUPERIOR: ENFOQUE PUBLICITÁRIO}


As mudanças que vêm acontecendo no cenário social oferecem condições para que haja demanda crescente no sistema educacional brasileiro; as pessoas querem oferecer para si e aos filhos o melhor para que possam ter um futuro adequado.

Os poucos filhos, principalmente da classe $\mathrm{C}$, vêm tendo uma infância privilegiada, em termos de consumo. O primeiro item de sua criação é a escola particular e mesmo que a escola particular não seja de primeira linha, é preciso acompanhar os coleguinhas (AZEVEDO e MARDEGAN-JR, 2009, p. 92).

Não há dados sistematizados oficiais sobre a participação das classes sociais no ensino superior brasileiro, mas estima-se que a classe C passou de $18 \%$ para $23 \%$ do público atendido pelas instituições de ensino superior no período de 2005 a 2009 (GORGULHO, 2009).

Segundo o Censo da Educação Superior 2011 do Ministério da Educação e Cultura/Inep ${ }^{3}$, havia em 2010 um total de 6.739 .689 alunos matriculados no ensino superior brasileiro (em 2000 eram cerca de 2,7 milhões). Existem estudos que preveem um contingente de 10 milhões de estudantes universitários no Brasil em 2020, estudos estes que condicionam essa meta ao ingresso da classe emergente nas faculdades brasileiras (CIEGLINSKI, 2012). Para tanto, é necessário discutir e implementar modificações na metodologia educacional em que, além dos tradicionais cursos de bacharelado e licenciatura, haja cursos superiores de tecnologia e os cursos de educação a distância.

A maior adesão da camada popular emergente no ensino superior também depende da continuidade das políticas do Governo Federal no que se refere aos programas sociais, caso do ProUni, Escola da Família e o Financiamento Estudantil - Fies, além da oferta de crédito ao consumidor em geral, condição necessária para continuar, principalmente, na escola particular.

No que tange às IES particulares, além da expansão do número de vagas, houve as que optaram em adotar políticas de incentivo para a camada popular emergente por meio de redução de preço dos cursos, parcelamentos, bolsas parciais e integrais, descontos e promoções, por exemplo, na aquisição de material didático.

As estratégias de marketing das IES focadas na camada popular emergente têm abordado questões que vão desde a oferta de cursos convenientes às perspectivas desse perfil

\footnotetext{
${ }^{3}$ Sinopses Estatísticas da Educação Superior - Graduação. Portal INEP, Brasília. Disponível em: http://portal.inep.gov.br/superior-censosuperior-sinopse. Acesso em 9 nov. 2012.
} 
de aluno, até a adequação financeira, no caso das particulares, para que ele ingresse, curse e conclua o curso.

Muitas IES têm se valido de modelos de estratégias de marketing focadas no aspecto econômico, já que a camada popular emergente considera de maneira privilegiada as despesas financeiras quando da escolha de um curso superior. Porter, por exemplo, denomina como vantagem competitiva focada no custo a estratégia de marketing ancorada no baixo preço e vantagens econômicas (PORTER, 1989).

Lauterborn (1990) oferece o modelo que retrata os 4C's (Cliente, Custo, Conveniência e Comunicação), cabendo aqui destaque ao elemento Custo, que não se limita ao preço, mas agrega outros fatores que oneram o consumidor, como o gasto de tempo, gastos emocionais, gastos adicionais para poder usufruir um produto ou serviço, ou seja, uma complexa equação de custo-benefício realizada em cada aquisição.

Para Fox e Kotler (1994), a percepção dos consumidores quanto ao preço vai muito além de uma despesa em si, já que o custo se estende a decisões no âmbito do preço/qualidade, preço/renda, conveniência do preço face ao esforço de aquisição, adequação do custo em relação à gratificação obtida pela escolha e outros. Em muitos casos, quando os preços são similares, o consumidor foca seu olhar para a qualidade oferecida. Segundo os autores, o preço efetivo é compreendido, na educação superior, como a quantia paga pelo aluno ou sua família em termos monetários. A redução relativa de preço é entendida por depreciação do valor monetário, caso da redução de tempo que permite ao aluno, por exemplo, concluir sua graduação em dois anos, ou obter acesso e desconto em sistemas de pós-graduação.

Outros aspectos que integram as decisões relativas a custo são descontos, vantagens, programas de incentivo, formas de pagamento, isenção de taxas, bem como a otimização de tempo.

As estratégias adotadas pelas IES referentes ao custo trabalham elementos que conferem descontos promocionais, redução de valores quando se trata de pagamento em data pré-determinada, parcelamento de taxas, isenção destas, bolsa de estudo, programas de financiamento estudantil etc.

Custo consiste no preço das mensalidades, valores na aquisição de serviços e custos para dispor dos serviços educacionais (custo de estacionamento, de tempo para locomoção, refeições, custo emocional para lidar com atividades prazerosas ou maçantes etc.). Normalmente, o preço em si é fator fundamental na opção de uma IES particular, mas outros fatores também concorrem, caso da relação custo-benefício do curso e conteúdos 
enriquecedores para a vida profissional e pessoal do estudante (BITTENCOURT e GIACOMINI-FILHO, 2008, p.216).

\section{A COMUNICAÇÃO DAS IES VOLTADA PARA CAMADA POPULAR EMERGENTE}

O potencial mercadológico e os atributos valorizados pelas classes econômicas $\mathrm{C}, \mathrm{D}$ e E representam desafios para a publicidade, pois reúnem um contingente com necessidades e desejos específicos para ser atendido pela comunicação publicitária (SILVEIRA, 2004).

Farias (2007) sugere que as empresas e agências de propaganda revejam alguns mitos sobre os consumidores de baixa renda tais como: só procuram preços baixos, têm pouco dinheiro para gastar, só gostam de coisas simples, pois hoje esse consumidor releva a relação custo-benefício e, a marca que melhor o atender, poderá obter sua fidelização.

Considerando as práticas publicitárias usuais, a linearidade na construção da mensagem é um dos primeiros pontos a ser pensado quando se constrói uma peça para o público de menor poder aquisitivo, em tese porque este aprecia a informação mais direta a respeito do produto que lhe é ofertado. Seria uma comunicação com começo, meio e fim; didática, com termos compreensíveis, locais reconhecíveis e situações que possam levar o observador a se interessar, desejar e agir para obter o bem anunciado (FARIA e GIACOMINIFILHO, 2011).

A propaganda, nesse contexto, tem no custo um grande atrativo. O custo se refletirá nas formas de pagamento, economia de gasto, vantagens especiais em programas de relacionamento, enfim, fatores que se mostram vantajosos face às limitações orçamentárias e de renda que possuem os integrantes da camada popular emergente. Tal característica é extensiva aos anúncios das IES, que assinalam os valores das mensalidades, concessão de bolsas de estudo, acesso a sistemas de financiamento próprios ou do governo, campus em locais de acesso via transporte público, dentre outros.

Não se pode determinar quando ou qual setor construiu as bases que hoje configuram a comunicação publicitária para as camadas de menor poder aquisitivo, mas o setor de varejo tem oferecido, historicamente, intensa contribuição, sendo um dos anunciantes mais significativos as Casas Bahia (PRAHALAD, 2005).

A camada popular emergente evidencia para toda a indústria da comunicação a necessidade de se empreender constantes pesquisas com propósito de nutrir as campanhas publicitárias com elementos que contemplem conhecimentos realistas e efetivos sobre esse 
segmento. As IES compartilham também dessa necessidade, pois embora muitas dependam desse contingente, não foram verificados estudos sistematizados sobre a publicidade a serviço das IES no trabalho de marketing a fim de se comunicar com os segmentos de menor poder aquisitivo.

Essa situação, somada ao objetivo deste trabalho, inspirou a realização de uma pesquisa primária com anúncios de IES particulares. Para esse fim, optou-se pelo jornal Metrô News, jornal impresso distribuído em estações de metrô da cidade de São Paulo. O Mídia Kit ${ }^{4}$ do jornal Metrô News atesta a natureza popular do veículo: 58\% dos leitores pertencem às classes C e D; mostra também que os 150 mil exemplares são distribuídos gratuitamente em dias úteis.

A amostra se deteve em anúncios publicitários de IES veiculados no mês de novembro de 2011, com tamanho igual ou superior a $1 \frac{1}{4}$ de página. Foram 20 edições, totalizando 28 IES anunciantes, sendo que 49 se enquadraram no critério estabelecido.

A análise de conteúdo seguiu o modelo teórico de Bardin (2004), que prevê a eleição de categorias de análise e consequente tratamento analítico conforme o objeto de interesse do pesquisador, partindo de pontos que remetem ao referencial teórico trabalhado anteriormente no decorrer deste estudo, tanto de forma qualitativa como quantitativa. Neste caso, foram analisados apenas os fatores denotativos do anúncio, ou seja, conteúdos contextualizados no padrão estético de anúncios publicitários.

A análise de conteúdo privilegiou o elemento "custo" presente no modelo de Lauterborn (1990). O intento foi apurar o quão presente e relevante é o elemento "custo" na peça publicitária.

Para analisar os elementos que fizeram parte da mensagem diante do quesito "custo", áreas foram estipuladas na superfície de cada anúncio a fim de quantificar as peças publicadas por IES. Esta subdivisão da superfície do anúncio em áreas seguiu a lógica ou estrutura usada na montagem de outdoor padrão, pois, segundo Gracioso (2002), trata-se de uma tabuleta montada ao ar livre com cartazes de 32 folhas. Dessa forma, os anúncios publicitários de IES foram divididos em 32 áreas, possibilitando enquadramento quanto à incidência de elementos que remetem a custo.

A análise considerou elementos estéticos, expressões ou frases que remetessem ao elemento custo, caso do preço, descontos, formas de pagamento, bolsas, programas de incentivo, vantagens econômicas e termos que continham palavras correlatas.

\footnotetext{
${ }^{4}$ O Midia Kit elaborado pelo Metro News é auditado pela consultoria BDO, a partir de dados coletados pelos Estudos Marplan/EGM-Julho/10 -Dezembro/10, Grande São Paulo, instituto IPSOS.
} 
Dessa forma, dos 49 anúncios, 30 contemplaram explicitamente o custo em ao menos uma área (1/32 da área do anúncio), ou seja, 61,2\% dos anúncios indicaram o custo como elemento informativo e persuasivo, o que mostra ser o custo um elemento presente na comunicação publicitária destinada à camada popular emergente dentro da amostra considerada.

Esse percentual é semelhante se considerados os anunciantes, pois 17 das 28 IES $(60,7 \%)$ fizeram uso do custo no conteúdo publicitário.

A apresentação do elemento custo na forma de preço nominal (numérico) ocorreu em 23,2\% dos anúncios, ou seja, tais peças apontaram o valor expresso em reais ( $\mathrm{R} \$$ ) para que o consumidor tenha uma ideia do nível de preço ou base comparativa com outras IES. Além do preço nominal, apareceram com certo destaque nos anúncios os descontos (17,8\%).

Estabeleceu-se que, se o fator custo aparecesse em $25 \%$ ou mais das áreas do anúncio, poderia ser considerado como estratégico naquela peça publicitária. Dentro deste critério, 11 peças ou 9 anunciantes apresentaram o elemento custo como estratégico, o equivaleria respectivamente a $22,4 \%$ e $32 \%$ do total.

Esses números indicam que o custo, embora com peso significativo, não é elemento usado de forma única ou predominante na oferta publicitária para a camada popular emergente.

Segundo a análise de conteúdo efetuada, observou-se que o trabalho de criação publicitária utiliza várias expressões, palavras, frases ou recursos semânticos que remetem a custo, tais como: bolso, grana, dinheiro, preço, valor, prova/vestibular social, condições especiais, mensalidades, caro. Algumas palavras parecem pertencer a um jargão popular (bolso, grana) que remetem a uma vantagem econômica, enquanto outras são mais diretas: dinheiro, preço, valor, caro, mensalidade (custo). Há algumas que parecem indicar um apelo promocional de curto prazo, oportunidades ou vantagens em termos de custo-benefício: prova/vestibular social, condições especiais.

\section{CONSIDERAÇÕES FINAIS}

Este artigo objetivou analisar a comunicação publicitária envolvida na relação das instituições de ensino superior para com a camada popular emergente. Em que pese as limitações desta pesquisa diante da extensão do objeto de estudo e o caráter exploratório do trabalho, pode-se afirmar que tal intento foi alcançado. 
O primeiro grande desafio foi oferecer bases conceituais para o termo "camada popular emergente", uma vez que tal termo não tem construção plena e é um dos pilares temáticos da pesquisa. Tal construção ocorreu a partir dos fatores econômicos, sociais e políticos eclodidos nos anos 1980 e que propiciaram ganho de renda, poder de consumo e inserção sociopolítica para um contingente predominante nas classes C, D e E. Tal emersão repercutiu nas IES, fazendo o setor desenvolver estratégias de marketing focadas no custo, estratégias estas que demandaram esforço especializado por parte da comunicação publicitária destas IES.

Outro grande passo teórico e necessário foi o de caracterizar as instituições de ensino superior em termos de estratégias de marketing já que são organizações e anunciantes chaves no estudo. As organizações educacionais voltadas ao ensino superior registraram o dobro de matrículas no período de 2000 a 2010, algo diretamente ligado ao ingresso da camada popular emergente no mercado de consumo. É plenamente possível crer que as estratégias de marketing e os esforços publicitários para lidar com esse contingente tenha se inspirado em outros setores do mercado e que, recentemente, tenha desenvolvido conhecimentos e práticas especializadas, como as estratégias com foco no consumidor e no custo.

De um lado, a comunicação publicitária focada no custo não pode ser entendida como aquela que se apega apenas ao fator econômico, pois, para ser aceita no contexto da camada popular emergente, é necessário que o anúncio da IES agregue qualidades adicionais, inclusive pela competitividade que alcançou o setor.

Para tanto, a pesquisa primária com anúncios publicitários de IES realizada na amostra aqui apresentada, apurou que $61,2 \%$ dos anúncios possuem conteúdos alusivos ao custo. Esse dado, no entanto, precisa ser completado com outro que aponta serem minoria os anúncios em que o fator "custo" aparece de forma destacada, como se evidenciasse melhor uma estratégia de marketing voltada ao custo. Visto por esse ângulo, apenas $22,4 \%$ das peças ou $32 \%$ dos anunciantes apresentaram o elemento custo como estratégicos, o que corrobora com a premissa de que além do custo, é necessário agregar conteúdos que acentuem benefícios e gratificações ao cliente potencial.

O referencial teórico sustentou que as pessoas da camada popular emergente não valorizam apenas os aspectos econômicos (custo), mas também qualidade, conveniência, localização, perspectiva de emprego, projeção social entre outros fatores. Assim, a pesquisa com anúncios reforça que a publicidade de IES voltada para tal público precisa levar em conta múltiplos elementos e não apenas os relacionados a custo. 
Mas, por qualquer ângulo que se queira analisar os números encontrados, é certo que o fator "custo" integra-se como elemento informativo e persuasivo em anúncios publicitários de IES voltados para a camada popular emergente.

Nesse sentido, vale comentar que a análise não teve por pretensão rotular a IES como focada na camada popular emergente, mas apenas discorrer sobre as peças veiculadas e, nelas, sugerir esse vínculo.

A criação publicitária em evidenciar o preço nominal, descontos e os elementos relativos ao custo pôde indicar também o alto grau de competitividade que chegou o setor educacional, notadamente as IES, inclusive com a possibilidade de vários concorrentes disputar o mesmo mercado, neste caso a camada popular emergente.

Tais desafios demandam para a publicidade inovações tendo em vista uma estratégia mercadológica mais ampla e afinada com um consumidor que exalta o custo-benefício, mas que aparentemente é atento a uma oferta que faça sentido a sua visão de qualidade de vida.

A incursão de IES em estratégias focadas no custo mostra uma mudança de postura do setor do ensino superior. A se referenciar pelos estudos encontrados, o setor publicitário ainda está passando por um aprendizado tendo em vista que essa inovação deve estar incorporada adequadamente nas campanhas e anúncios.

Poucos foram os estudos sistematizados realizados sobre a comunicação publicitária das IES para com a camada popular, talvez porque esse contingente fosse economicamente pouco relevante no passado, mas que hoje torna-se foco para investimentos comunicacionais.

Cumpre destacar que os resultados aqui alcançados e comentados não podem ser generalizados face aos limites da amostra e ao tipo de pesquisa (exploratória).

Outros estudos podem ser conduzidos nesta temática, caso de se verificar se o modelo atual publicitário possui características corretas de especialização, ou ainda se oferece um tratamento estereotipado em anúncios destinados às camadas de menor poder aquisitivo, o que poderia acarretar depreciação da credibilidade da IES e afetar seus intentos de marketing no curto e longo prazos.

A camada popular emergente mostra relevância e complexidades que precisam ser melhor estudadas, particularmente no que se refere à indústria da comunicação, inclusive para que os aspectos de eficácia e ética tenham sintonia com a realidade atual.

\section{REFERÊNCIAS}


AZEVEDO, Marcelo da R.; MARDEGAN-JR., Eliseu. O consumidor de baixa renda. Rio de Janeiro: Ed. Campus. 2009.

BARDIN, Laurence. Análise de Conteúdo. Lisboa: Edições 70, 2004.

BITTENCOURT, Vítor; GIACOMINI-FILHO, Gino. Marketing: estratégias e casos brasileiros. In: Estratégias Empresarias: pesquisas e casos brasileiros. LAMENZA, Ademir (org.). São Paulo: Saint Paul Editora, 2008, p. 175-222.

CIEGLINSKI, Amanda. Rumo aos 10 milhões. Ensino Superior. São Paulo: SEMESP, n ${ }^{\circ} 60$, 2012, p. 30-35.

D’ANDREA, Guillermo et al. Crear valor para los consumidores emergentes. Harvard Business Review. Vol. 81, n. 11, 2003, p. 124-133.

SOUZA, Amaury de; LAMOUNIER, Bolivar. A classe média brasileira - ambições, valores e projetos de sociedade. Rio de Janeiro: Elsevier, 2010.

EARP, Fabio Sá; PAULANI, Leda. Mudanças no consumo de bens culturais no Brasil após a estabilização da moeda. Rio de Janeiro: IE-UFRJ, 2011. Disponível em:

<http://www.ie.ufrj.br/images/pesquisa/publicacoes/discussao/2011/IE_Earp_Paulani_2011.p df>, acesso em 20 abr. 2012. 36p.

FARIA, Ewerton M. V.; GIACOMINI-FILHO, Gino. Comunicação Especializada e a Estratégia de Preço Baixo. São Paulo: Confibercom, 2011. Disponível em: < http://confibercom.org/anais2011/pdf/114.pdf>, acesso em 26 abr. 2012.

FARIAS, Ana P. G. Os consumidores de baixa renda - A comunicação no setor de higiene pessoal, perfumaria e cosméticos. 2007. Dissertação (Mestrado em Comunicação Social) Universidade Metodista de São Paulo.

FOX, Karen F. A., KOTLER, Philip. Marketing Estratégico para Instituições Educacionais. São Paulo: Atlas, 1994.

GORGULHO, Vinícius. A nova classe média vai à escola. Ensino Superior. São Paulo: SEMESP, v. 12, n. 134, nov. 2009, p. 34-36.

GRACIOSO, Francisco. Propaganda: engorda e faz crescer a pequena empresa. São Paulo: Atlas, 2002.

LAUTERBORN, Bob. New marketing litany: four Ps passe: C-words take over. Advertising Age. New York, v.61, n. 41, out. 1990, p. 26.

NERI, Marcelo. A nova classe média: o lado brilhante da base da pirâmide. São Paulo: Saraiva, 2011.

O'NEILL, Jim. O mapa do crescimento: oportunidade econômicas nos BRIC's e além deles. São Paulo: Globo, 2012.

PORTER, Michael. Vantagem Competitiva: criando e sustentando um desempenho superior. Rio de Janeiro: Campus, 1989. 
PRAHALAD, Coimbatore K. A riqueza na base da pirâmide: como erradicar a pobreza com o lucro. Porto Alegre: Brookman. 2005.

ROMANELLI, Geraldo. Questões teóricas e metodológicas nas pesquisas sobre família e escola. In: Itinerários de pesquisa: perspectivas qualitativas em Sociologia da educação. ZAGO, N.; CARVALHO, M. P.; VILELA, R. A. T. (orgs). Rio de Janeiro: DPDP\&A, 2003.

SILVEIRA, Cynthia M. S. A voz e a vez dos populares: os consumidores de baixa renda. 2004. Dissertação (Mestrado em Comunicação Social) - Universidade Metodista de São Paulo.

TORRETA, André. Mergulho na base da pirâmide: uma oportunidade para sua empresa. São Paulo: Saraiva, 2009.

WILLIANS, Raymond. Base e superestrutura na teoria cultural marxista. Revista USP (online). São Paulo, v. 66, mar./maio 2005, p. 210-224. Disponível em: < http://www.revistas.usp.br/revusp/article/view/13448/15266 >, acesso em 29 mar. 2012.

Original recebido em: 04/02/2013

Aceito para publicação em: 25/07/2015

Ewerton Mauro Visotto Faria

Mestre em Comunicação pela Universidade

Municipal de São Caetano do Sul. Coordenador e professor dos cursos de

Comunicação Social da Faculdade

Anhanguera de São Caetano do Sul.

Gino Giacomini Filho

Doutor e Livre-docente em Comunicação Social pela Escola de Comunicações e Artes da Universidade de São Paulo. Docente do Mestrado em Comunicação da Universidade Municipal de São Caetano do Sul (USCS). 